International Journal of Electrical Engineering and Technology (IJEET)

Volume 11, Issue 4, June 2020, pp. 404-411, Article ID: IJEET_11_04_045

Available online at https://iaeme.com/Home/issue/IJEET? Volume $=11 \&$ Issue $=4$

ISSN Print: 0976-6545 and ISSN Online: 0976-6553

DOI: https://doi.org/10.34218/IJEET.11.4.2020.045

\title{
HIGH VOLTAGE ENGINEERING USING ACTIVITY BASED LEARNING
}

\begin{abstract}
M. Ramu
Assistant Professor, Department of Electrical Electronics and Communication Engineering, (GITAM) - Gandhi Institute of Technology and Management, India
\end{abstract}

\section{Anand Kishore Azad}

PG Scholar, Department of Electrical Electronics and Communication Engineering, (GITAM) - Gandhi Institute of Technology and Management, India

\section{A. Rohit}

PG Scholar, Department of Electrical Electronics and Communication Engineering, (GITAM) - Gandhi Institute of Technology and Management, India

\section{ChandraSekhar}

UG Student, Department of Electrical Electronics and Communication Engineering, (GITAM) - Gandhi Institute of Technology and Management, India

\begin{abstract}
This 21 'st century, change drastically for teaching and learning system. Now a days few students are showing their interest in learning information from the teacher rest is purely depending on Internet resources like Google, YouTube and other Platforms etc. It means in any manner many students easily learn any course from outside if they not comfortable in learning it. So as a teacher we have to create interest in these type of subject through implement different techniques, Activity-Based Learning $(A B L)$ is one of these technique which acts as a method to overcome from the convectional technique of studies. In this way Classroom bases ABL activities will give simultaneous benefits to both students as well as for teachers in the manner students can overcome their difficulties in learning typical course and teachers can deliver a topic in a variety of approaches more effectively [1]. High Voltage Engineering one of the fast developing technology within the electrical engineering field. This paper presents the results and experiences gained from Design-Oriented Project Based Learning of High Voltage power supply design within a High Voltage Engineering at the Gandhi Institute of Technology (GITAM). Project-based learning $(P B L)$ is one of the Activity base learning method that provide motivating and problem-centered teaching facilities that places students the ability to transfer their acquired scientific knowledge into industrial practices. And also provide students under the core of the teaching and learning activities [2].
\end{abstract}


Key words: ABL (Activity based learning), PPT (Power point presentation).

Cite this Article: M. Ramu, Anand Kishore Azad, A. Rohit and D. Chandra Sekhar, High Voltage Engineering Using Activity Based Learning. International Journal of Electrical Engineering and Technology, 11(4), 2020, pp. 64-71.

https://iaeme.com/Home/issue/IJEET?Volume $=11 \&$ Issue $=4$

\section{INTRODUCTION}

There are only three basic needs of human that Is food, cloth, and shelter but now a days there is also $4^{\text {th }}$ basic need of human that is electrical Power. Humans totally depend on the environment for these need and with those resources a man had initiated the search of science. Technology has been updated a lot with many discoveries and inventions which made our life very much comfortable and convenient too in this century. And for operate any electrical device we need Electric Power got from any sources. The man's life is incomplete exactly without power supply these days [3]. Everyone can

Utilize the electric power for their needs at the same time must have to take a responsibility to save it too for future generations. It is a necessary subject in the discipline of Electrical Engineering.

\section{List of Activities Implemented}

To develop the different techniques for teach High voltage engineering to the engineering student and provide more deep knowledge and keen interest we adopt these following methods:-

- Interdisciplinary

- Use of different computer software

- Case Study PPT's

- Virtual learning

- Capstone projects

- Graded assignment

- Power Grid Visit and identification of different types of the transmission system

Layout of the Course Structure HVAC Transmission System in Our University.

The course of HVE is compressed in class lectures and group work. The overview of each and every main component and about subject given in class lecture, the group work concentrates on making the paper design of a HVAV transmission system. After end of the course, every student should be able to delivers a final report which describe the theoretical analysis as well as design results, and for final assessment also an oral examination arranged [4].

The main learning elements which are used for this objective is as follows:-

- Understanding different HVAC and HVDC transmission topologies and design a model according to the specifications successfully;

- Implementing the effective cooperation with others within the specific design project in order to distribute.

- Self-directed learning in multidisciplinary knowledge;

- workload, analyzing problems and helping each other;

- Writing technical reports and presenting one's own work to others including the external examiner. 


\section{USE OF ACTIVITIES IMPLEMENTED}

\subsection{Interdisciplinary Approach}

An approach to make the curriculum more integrated that creates an understanding of the course theme and ideas that come under the discipline and also make connection between the different discipline and their relationship in the practical world.

In this activity team of professors and learner come from different institute and discipline come to our college and give proper introduction of this course in the form Workshops, and on Hand trainings offered by NPTI(National Power Training Institute) and Power grid.

\subsection{Use of Different Computer Software}

Adapting this approach create an interest to the students for understanding the proper knowledge of the course by using the different software provided by different platforms. These are :-

- Orcad PSpice

- LTspice

- Matlab

\section{LTspice}

LTspice provides schematic capture to enter an electronic schematic for an electronic circuit, and Provide SPICE type electronic circuit simulator, and give a waveform viewer to show the results of the circuit simulation.

Circuit simulation analysis based on AC, DC, DC transfer function, transient, noise, DC operating point that can performed and plotted [8]. Heat dissipation of components can be calculated and efficiency reports can also be generated. This software consist of enhanced and specialized models of simulation for HVDC components and transmission line parameter.

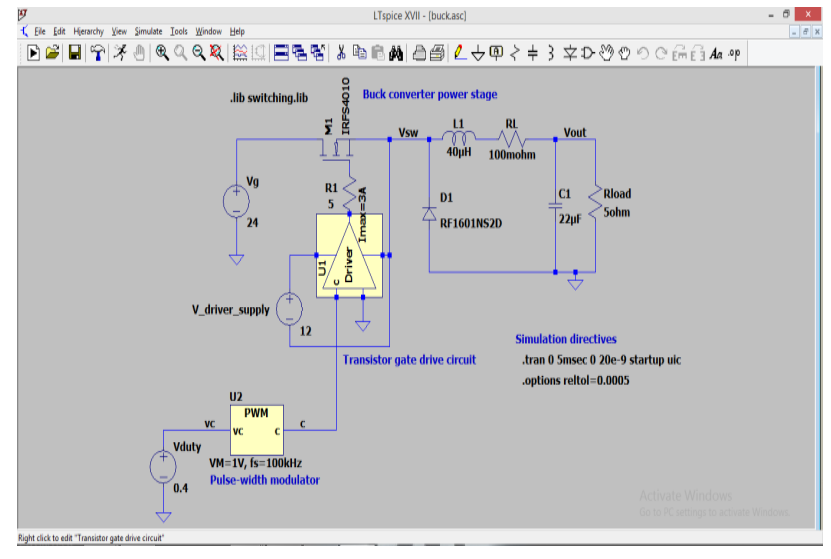

Figure 1 Circuit Simulator used for HVDC components

\section{Orcad PSpice}

This software contains distributed and lumped transmission lines used for help to improve the reliability of the transmission system. Due to this advantage of software we used this to provide practical knowledge of this course including every parameters and problems system. the frequency response of circuits with transmission lines can also be analyzed. It is the purpose of this article to examine the steps and issues involved in modeling and analyzing transmission lines in PSpice. The Flowchart of the steps using in the software shown in figure 1. 




Figure 2 Flowchart using in PSpice software

\section{MATLAB}

MATLAB (Matrix Laboratory) is a programming environment for algorithm development, data analysis, visualization, and numerical computation, developed by MathWorks. MATLAB is widely used for for matrix-based computation designed for scientific and engineering use.

We use this software for our learning to provide integrates computation, programming and visualization in an easy-to-use environment where problems and solutions are expressed in familiar mathematical notation.

\section{Connecting to the Grid}

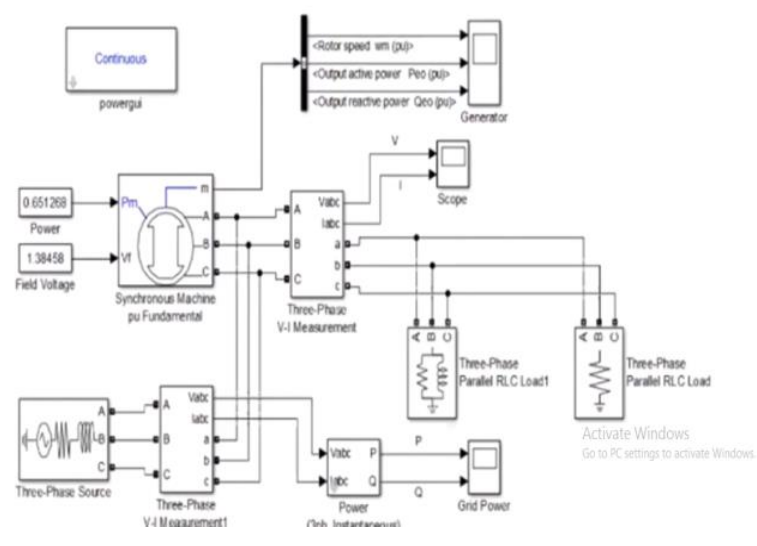

Figure 3 Use of HVDC component connecting to grid in MATLAB 


\section{CASE STUDY PPT'S}

PPT is a file extension for a presentation file format used by Microsoft PowerPoint, the popular presentation software commonly used for office and educational slide shows. All text images, sound and video used in the presentation are contained in the PPT file [8]. Here we use this PowerPoint software to provide the knowledge regarding our course using different types of Gif Image, Videos and animation allows us to create proper slide show to support a presentation. we combine different text, graphics and multi-media content to create interesting presentations to give better approach to our courses.

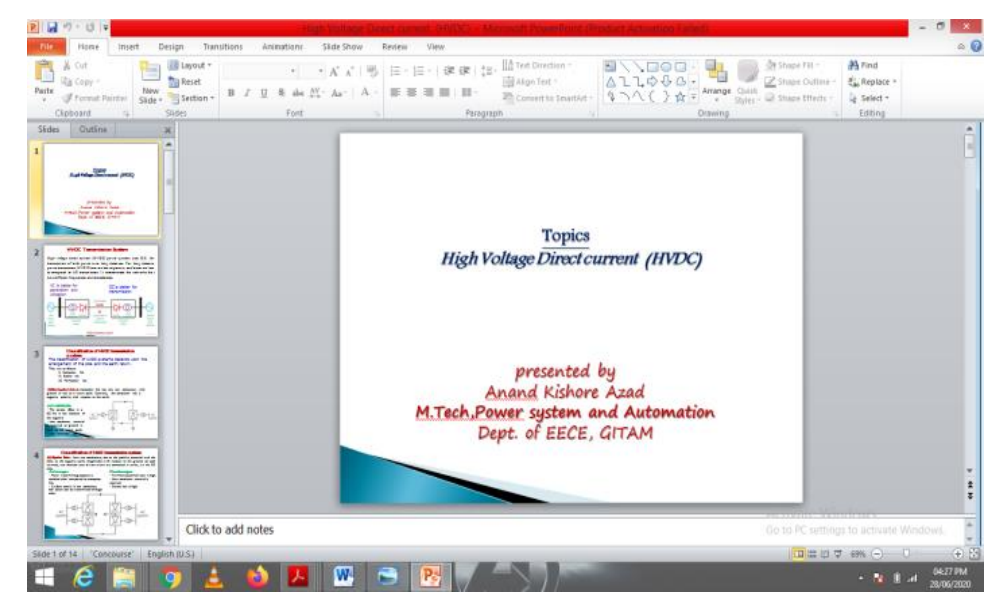

Figure 4 Use of PPT Slides for HVDC
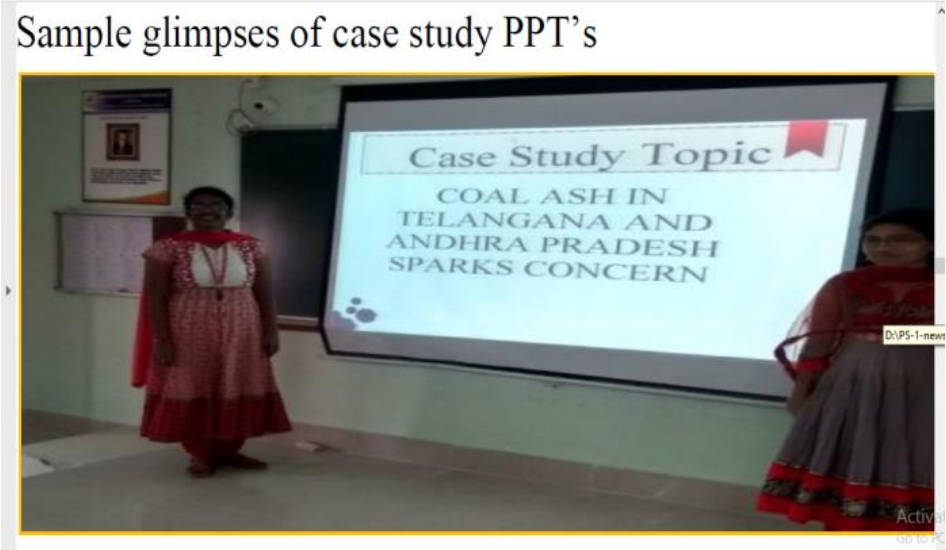

Figure 5 Giving lecture about previous case study regarding HVDC transmission lines

\section{VIRTUAL LEARNING AND ITS APPLICATION}

Virtual reality is the technique that aims to eliminate interaction barriers between users and computer systems. It also Provide the human sense simulator for give impression of presence inside the 3D mode in computer environment. Virtual reality can be classified in two groups: immersive and VR non-immersive desktop-based VR. We used for our teaching process Immersive VR that requires head mounted displays and interaction devices like data gloves or joysticks and multi directional thread mills coupled with advanced visualization systems like the cave automatic virtual environment. The special interface use here provides the student to isolate from the physical world and provide a deeper sense of presence of the main component of the course. These applications provide a high level of interactivity and realism. 


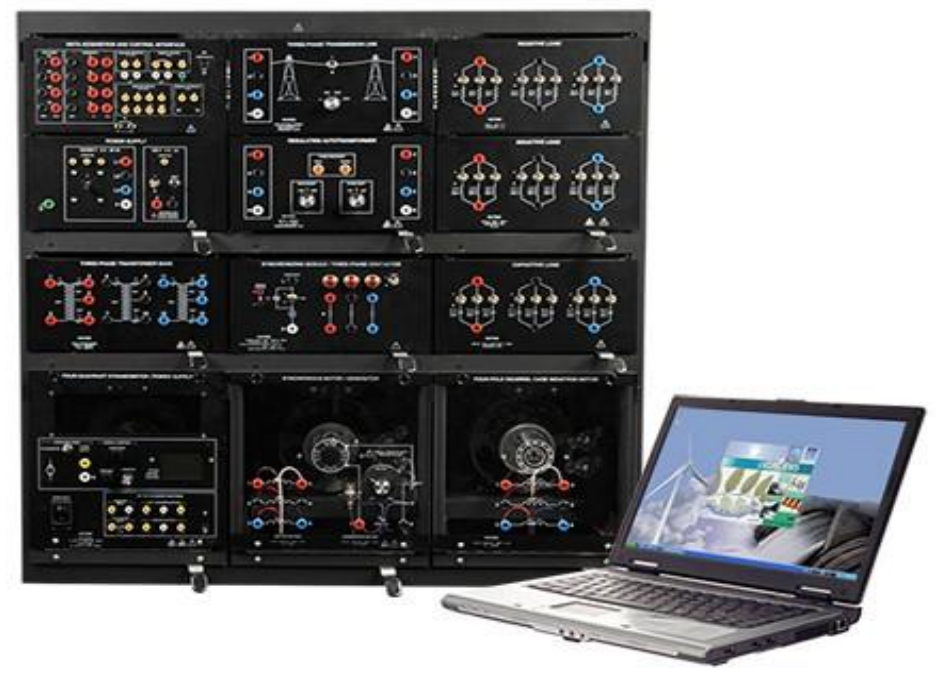

Figure 6 Transmission line model for Virtual Reality teaching process

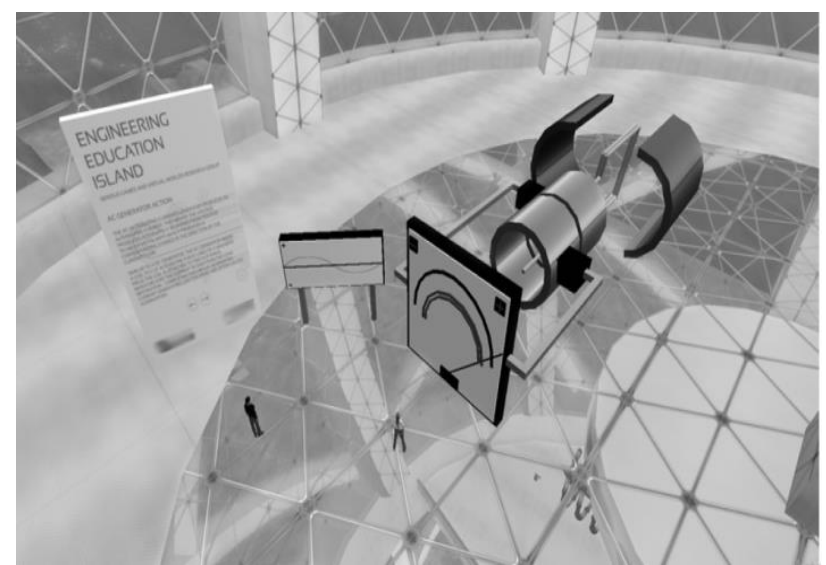

Figure 7 AC generator demo inside the virtual engineering laboratory

\section{CAPSTONE PROJECT}

In the final task of their academic course a simply and highly extensive project work that is done by the student applied all their gained knowledge in the form of capstone Project. The capstone is more or less a research project. The student will write a proposal in the area they wish to do and they will need to produce high-quality original research. It may also in the form of a practical project [8].

Capstone ventures are commonly give chance to think fundamentally, create aptitudes, and take care of testing issues that give abilities that will help to set them up for higher studies, present-day professions, and grown-up life. By and large, the activities are likewise interdisciplinary, as in they expect understudies to apply aptitudes or examine issues across a wide range of branches of knowledge or areas of information. These projects are in different form like :

- Simscape Electrical using MATLAB

- Circuit Design with Proteus

- GSM based Substation Monitoring and Control System

- Arduino Projects 


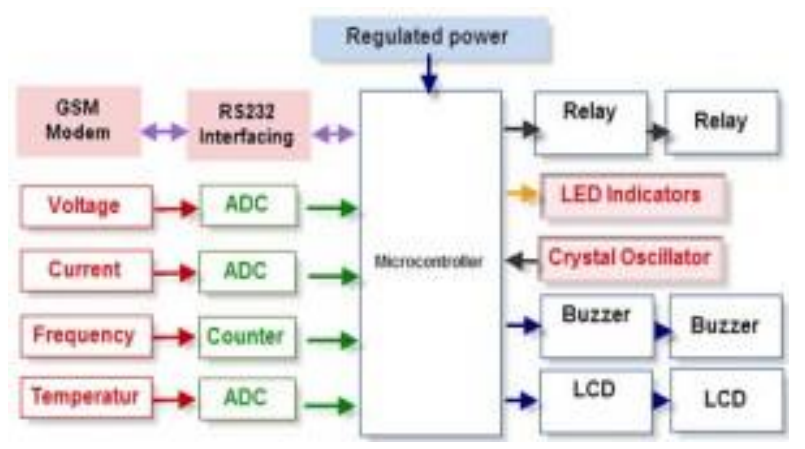

Figure 8 GSM based Substation Monitoring and Control System

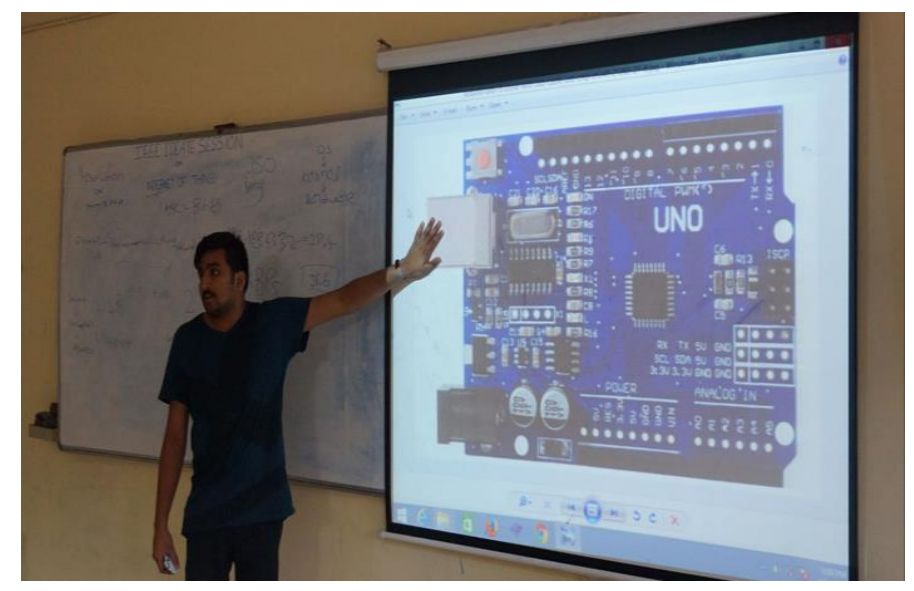

Figure 9 Arduino Projects on HVDC Model

\section{GRADED ASSIGNMENT}

At the time of reviewing assignment submissions, we can provide a grade and also ask for the feedback. We also give chance for returning the submission to the student with comments only, so the assignment can be refined further and then resubmitted for a grade. The steps taken here by us is as follows:

QUICK STEPS: grading assignments

- Viewing of the submitted text, attached files, and comments made by the student on the Grade Assignment page.

- Provide instant Grades for every assignment.

- Optionally, type comments in the Feedback to User box and attach a file for the student to review.

- Use of the Text Editor functions to format the text and add files, images, links, multimedia..

- Optionally, type comments in the Grading Notes box and attach files that only particular student can access.

\section{POWER GRID VISIT AND IDENTIFICATION OF DIFFERENT TYPES OF THE TRANSMISSION SYSTEM}

For Provide onsite knowledge and interest of the course we take our students for one day visit on Power Grid and substation that give them the intellectual knowledge about the course and they able to understand about every part that they study in the classroom. 


\section{CONCLUSION}

If a student want to learn Best then he/she must be involve in the teaching learning process as an active role player. but it only happen if the habit of involvement is grown up in nature of the student, To working in team for a project give them chances to interact with team members and also to share their knowledge of different discipline. By adapting these activitybased learning students can learn how to make mistakes and overcome from that. ActivityBased Learning (ABL), made students learn various topics of High voltage engineering in different ways also to know the importance of this course. These classroom activities motivate and create keen interest in learning High Voltage engineering courses.

\section{REFERENCES}

[1] J.Venkatesh, (2019) Activity-based Learning (ABL) of Power Systems-I (PS-I) Course International Journal of Engineering Research \& Technology (IJERT) Vol. 8 Issue 12.

[2] Zhang, Zhe; Hansen, Claus Thorp; Andersen, Michael A. E. Teaching Power Electronics with a Design-Oriented and Project-Based Learning Method at the Technical University of Denmark Published in: I E E E Transactions on Education

[3] Aniruddha Biswas, Sumit Das and Suchandan Ganguly, (2018) Activity-Based Learning (ABL) for Engaging Engineering Students, Springer Nature Singapore Pte Ltd.

[4] Callaghan, Michael \& McCrory, Kerri \& Losada, J. \& Harkin, Jim \& Wilson, Shane. (2010). Teaching Engineering Education Using Virtual Worlds and Virtual Learning Environments. 295 - 299. 10.1109/ACT.2009.80.

[5] Andre's Ayala Garci'a1,Israel Galva'n Bobadilla, Gustavo Arroyo Figueroa, Miguel Pe'rez Ramı'rez, Javier Muñoz Roma'n, (2016) Virtual reality training system for maintenance and operation of high-voltage overhead power lines, Springer Virtual Reality, 20:27-40 DOI 10.1007/s10055-015-0280-6.

[6] G-Quiz tool for conducting quiz, student polls, assignments, course material sharing etc.

[7] Youtube animation videos of thermal/nuclear/gas power plants operation and working in 3-D view.

[8] Google/Wikipedia for information about various power systems - I (PS-I) topics.

[9] Google forms to collect student feedback about impact of Activity Based Learning (ABL) in learning Power Systems-I (PS-I).

[10] CMA. Dr. C. Samuel Joseph, Dr. F.J. Peter Kumar and Dr. R. Magesh Kumar, (2019) Implementing Activity Based Costing Among Automotive Engineering Industries in Small and Medium Enterprises Sector of Tamil Nadu, International Journal of Mechanical Engineering and Technology, 10(01), pp.550-563 